\title{
An Investigation Of Perceived Risk Of Body Weight Among Normal And Overweight: Can Consumer Perceived Risk Theory Help?
}

Alican Kavas, Winston-Salem State University, USA

Aysel Kavas, Winston-Salem State University, USA

\begin{abstract}
Weight-related problems such as obesity and eating disorders are among the most prominent public health concerns with serious health and economic consequences. Risk perception related to weight is one of the strongest predictors of intention to manage weight and the practice of eating healthy diets. This study explores the feasibility of adapting perceived risk theory from consumer behavior research to perceived weight risks, and investigates the differences in perceived weight risk between normal and overweight consumers, and in their weight-related behaviors. The findings indicated that the overweight and normal weight consumers differed in their perceived weight risks in all risk dimensions. However, this difference was not reflected in their food consumption behaviors and physical activity levels which are indications of weight management efforts.
\end{abstract}

Keywords: Perceived risk, weigh- related problems, perceived weight risk, risk management

\section{INTRODUCTION}

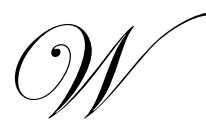

eight-related problems such as obesity and eating disorders, are among the most prominent public health concerns in the United States. Obesity, for example, has skyrocketed in the last thirty years. Among adults, obesity rates more than doubled from the early 1970s to the late 1990s. These alarming trends have received a great deal of attention in recent years. Researchers are anxious to understand the reasons underlying the trends and to investigate the consequences. There are health and economic consequences of weight-related problems for society in general and for individuals in particular. For example, by some estimates, 300,000 deaths a year may be attributable to obesity, making it the second leading cause of "preventable" death after smoking. Furthermore, obesity related problems are associated with increased costs for society and individuals in terms of physician visits, hospitalization expenses, lost wages due to sickness, disability, lower wages than those without weight problems, reduction in productivity, and psychological problems like depression and low self esteem (Cawley, 2000; Anderson et al. 2003; Roux and Donaldson, 2004). People with eating disorders, on the other hand, have a perception of being too fat and therefore engage in destructive eating behaviors in order to control their weight. It is estimated that 5-10 million women and 1 million men in the US suffer from eating disorders (Floyd et al. 2008).

Weight-related problems are considered to be a personal and a societal problem. These problems may stem from many personal factors, such as eating habits, physical inactivity, genes, and environmental and psycho-social factors such as the physical and social environment that promotes overeating or thinness and discourages physical activity (Wammes et al. 2005). Individuals may or may not perceive their weight (being too fat or too thin) and consequences of their weights (e.g., illness, low self-esteem, discrimination) as risk factors for their health. An 
understanding of perceived risk is critical for health education and communication efforts, and the perceived risk theory could shed some light on underlying differences in perception of weight risks.

The focus of this paper is to determine if there are differences in perceived weight risk as well as eating and activity behaviors among individuals. It is believed that determining perceived weight risks is important for the adoption of preventive behaviors in designing weight management and communication strategies. The paper proceeds as follows: First, perception of risk and risk types are explained as a conceptual model. Second, the methodology is explained and the results of an exploratory study are provided. Finally, the implications are discussed.

\section{CONCEPTUALIZATION OF PERCEIVED WEIGHT RISKS}

Perceived risk is fundamental to understanding individual consumer behavior. There are two traditions of research on consumer risk perception. The psychometric paradigm (Slovic, 1992) has focused on understanding of how people perceived health risks associated with different types of technologies (e.g. nuclear power) and how these perceptions vary given the different characteristics of each technology. The consumer behavior paradigm (Bauer, 1967; Cox, 1967; Cunningham, 1967) has sought understanding of how product purchases are affected by consumers' perceptions of financial, physical, performance, social or other risks associated with the purchase or use of a product. A perceived risk is defined as: "the uncertainty that individuals face when they cannot foresee the consequences" (Schiffman and Kanuk, 2007).

Figure 1: A schema of perceived weight risk

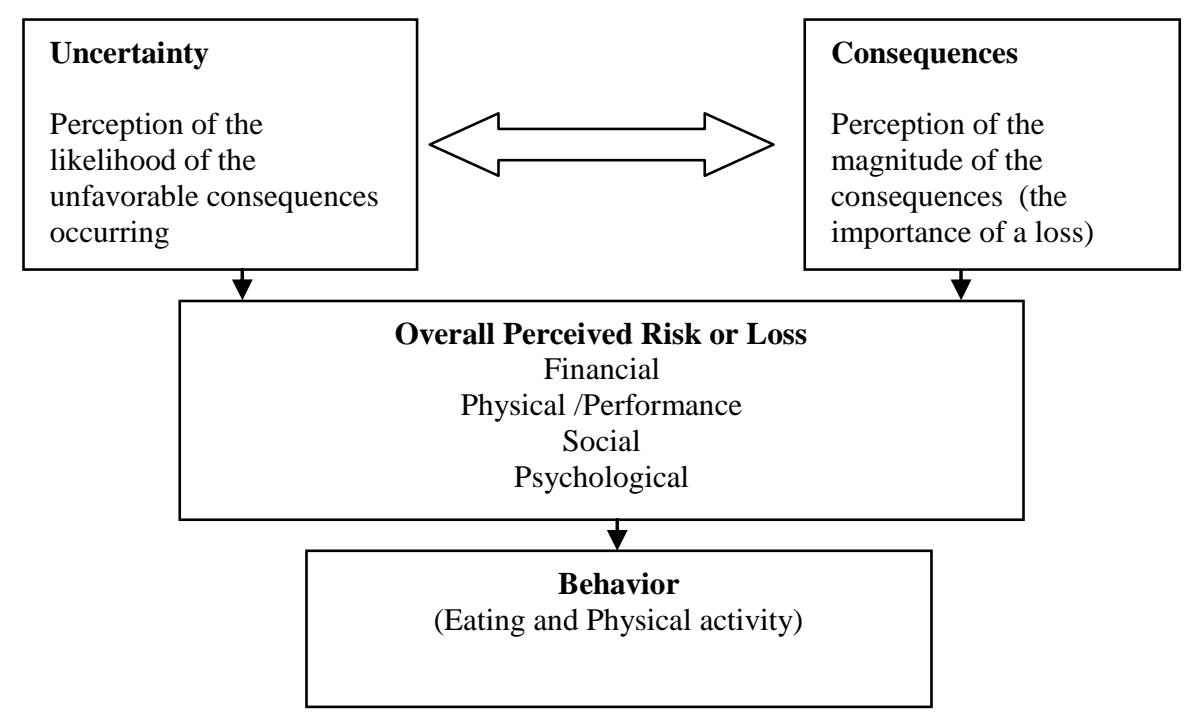

Perceived risk concept has been studied in a number of contexts such as food technology (Frewer et al., 1994), banking (Garner, 1986; Ho and Ng, 1994), retail patronage mode (Festerand et al., 1986; Schiffman et al., 1976), and online shopping behavior (Forsythe and Shi, 2003; Ko et al., 2004). In both sets of literature, risk is generally conceptualized as the probability of a loss of something of value to an individual in some context.

In this exploratory study, consumer behavior paradigm is utilized as a central theoretical foundation by adopting perceived risk concept to weight-related perception of risk and related behaviors. By doing so, the link between weight and risk perception can be assessed. Perceived risk was also described as comprising two 
components: uncertainty (likelihood of unfavorable outcomes) and adverse consequences (the importance of loss) (Cunningham, 1967; Dowling and Staelin, 1994). In addition to the two principal determinants of perceived risk, researchers have proposed that the uncertainty and consequences from a purchase can be divided into various dimensions of losses, including physical, performance, financial, social and psychological (Kaplan et al., 1974). Figure 1 illustrates the adapted schema of perceived weight risk.

In this study, these dimensions were adopted as perceived weight risk dimensions. The operational definitions of the adapted dimensions are shown in Table 2. Perceived risk, in turn, is correlated with intentions and behaviors (Stone and Gronhaug, 1993). In the perceived weight risk context, this means that perceived weight risk might influence the consumers' eating and physical activity behaviors. From the preceding discussion, the following research questions are derived:

a) Is there a difference between normal and overweight consumers with respect to their perceived weight risk? b) Is there a relationship between perceived weight risk, and eating and physical activity behaviors?

Table 1: Operational definitions of the dimensions of perceived weight risks

\begin{tabular}{|l|l|}
\hline \multicolumn{1}{|c|}{$\begin{array}{c}\text { Risk or loss } \\
\text { dimensions }\end{array}$} & \multicolumn{1}{c|}{ Operational definitions } \\
\hline Financial risk & $\begin{array}{l}\text { The likelihood of suffering a financial or economic loss due to weight-related problems (job loss, low } \\
\text { productivity, less pay, more health related spending, etc.) }\end{array}$ \\
\hline $\begin{array}{l}\text { Performance } \\
\text { /physical risk }\end{array}$ & $\begin{array}{l}\text { The chances of current weight-related problems deterring from functioning properly (loss of freedom in } \\
\text { valuable activities such as exercise) and resulting in physical harm or injury (health problems such as } \\
\text { heart diseases, hypertension, strokes, cancer, etc. and injury due to accidents, etc.) }\end{array}$ \\
\hline Social risks & $\begin{array}{l}\text { The likelihood of weight status resulting in others' thinking less favorable (embarrassment, disapproval by } \\
\text { friends) }\end{array}$ \\
\hline $\begin{array}{l}\text { Psychological } \\
\text { risks }\end{array}$ & $\begin{array}{l}\text { The chances of current weight status being inconsistent with the self image of the person (low self-esteem, } \\
\text { depression, body dissatisfaction, feeling of discrimination, negative effect on peace of mind) }\end{array}$ \\
\hline
\end{tabular}

Source: Adapted from Peter and Tarpey (1975) and Jacoby and Kaplan (1972).

\section{METHODOLOGY}

The design of the study is cross-sectional. A convenience sample of students from a Southeastern university participated in the study. The data were collected via a self-administered questionnaire from 86 undergraduate students which assessed demographics, self-reported weight and height, weight perceptions, food consumption behavior, and self-reported physical activity. After completion of the questionnaire, these students were weighed and had their height measured using a standard procedure in order to collect measured height and weight data. The correlation between self reported and measured height and weight was 0.90 .

Respondents expressed their level of agreement with nine statements about the perceived weight risks. Each statement was derived from the original dimensions of perceived risk used in consumer behavior research and adapted to perceived weight risks. The sample statement used was: "I have a low self-esteem because of my weight". A 4-point scale was used ranging from 1 (strongly agree) to 4 (strongly disagree) about each statement, with 1 representing highest perceived risk and 4 indicating lowest perceived risk for each risk statement. Cronbach's alpha reliabilities were calculated to determine the internal consistency of the overall perceived risk index and each dimension of the perceived risk. The overall perceived risk index internal consistency reliability measure was 0.90, and alpha of each dimension ranged from 0.50 to 0.79 (see Table 3). Financial perceived weight risk dimension had an alpha of 0.50 . Nunnally (1978) recommends an alpha threshold of 0.50 for exploratory work, therefore, it was accepted as satisfactory for the purpose of this exploratory study. Food consumption behavior (i.e., fat intake behavior) was determined by using The Behavior Change Consortium of the National Cancer Institute's Dietary Fat Intake Survey. A sample question was: "Do you consistently avoid eating high-fat foods?" Response categories were "yes" and "no". The self-reported physical activity level was determined by the following question, 
which was modified from Zimmerman et al. (2000) and CDC's Behavioral Risk Factor Surveillance System: "Which of the following best describes your current level of physical activity?" The response categories included "not physically active", "vigorously active (activities that cause large increases in breathing and heart rate), "moderately active" (activities that cause small increases in breathing and heart rate)" and "engage in light activities". Because of few responses to the extremes, responses were collapsed into two variables, physically active and inactive. Statistical analyses were performed with SPPS for Windows 15.0 version. Specifically, descriptive statistics, Chi square test, and t-test were conducted to analyze the data. The significance level was set at 0.05 .

\section{FINDINGS}

General characteristics of the sample are summarized in Table 2. Seventy three percent of the participants were in the 18-20 age group and sixty-four percent of the participants were female. The female sample proportion was consistent with the campus population. The average weight for the sample was 171 pounds; height was 66.9 inches, and BMI was 27 (overweight).

Table 2: Profile of the participants

\begin{tabular}{|c|c|c|}
\hline Demographics & $\mathrm{n}$ & $\%$ \\
\hline \multicolumn{3}{|l|}{$\underline{\text { Age }}$} \\
\hline$\overline{18}-20$ & 63 & 73.3 \\
\hline $21-23$ & 15 & 17.4 \\
\hline 24 and above & 8 & 9.3 \\
\hline \multicolumn{3}{|l|}{ Gender } \\
\hline$\overline{\text { Male }}$ & 31 & 36.0 \\
\hline Female & 55 & 64.0 \\
\hline \multicolumn{2}{|c|}{ Weight, Height and Body Mass Index (BMI) (a) } & Mean (Standard Deviation) \\
\hline Weight (in pounds) & & $171.0(44.6)$ \\
\hline Height (in inches) & & $66.9(3.64)$ \\
\hline BMI & & $27.0(6.60)$ \\
\hline
\end{tabular}

In several studies perceived weight has been shown to be a better predictor of weight control behaviors than actual weight (Brenner et al. 2004; Desmond et al.1986; Kumanyika et al. 1993; Strauss, 1999). Therefore, in this study, perceived weight (normal or overweight) was used to determine the differences in weight risk (Table 3). The mean values of overall perceived weight risk index (combining nine-item scores) for normal and overweight participants were significantly different. The participants who perceived themselves overweight also perceived a higher weight risk than the participants who perceived their weight normal. This finding is consistent with the expectations. The mean values of all four dimensions, namely, financial, physical/performance, psychological and social risks, were significantly different for the two groups. The overweight group perceived more financial, physical, psychological and social risks than the normal group because of their weight. When the individual risk items were examined, the mean of each item was lower for the overweight group than the normal group indicating that respondents who perceive themselves as overweight also perceive a higher weight risk in all items. However, when we used the measured height and weight to calculate BMI and then categorize the participants as normal and overweight based on their BMI and looked at their perceived weight risks, we found out that the overweight participants reported significantly higher perceived weight risks only in financial and physical/performance dimensions.

There may be sex and racial/ethnic differences in weight perception and health risk perceptions (Kumanyika et al.1993; Xie et al. 2006). Kumanyika (1993) illustrated that white men scored significantly lower on 
perceived health risk, women scored higher than men. On the other hand, non-white men and women gave comparable responses on health risk. We also looked at the gender differences in perceptions (data not shown), and showed no statistically significant differences between the weight risk perceptions of male and female participants.

Table 3: Mean perceived weight risks by weight perception

\begin{tabular}{|c|c|c|c|}
\hline Items (a) & $\begin{array}{l}\text { Total } \\
\text { Respondents } \\
\text { Mean (SD) }\end{array}$ & $\begin{array}{l}\text { Normal (b) } \\
\text { Mean (SD) }\end{array}$ & $\begin{array}{c}\text { Overweight (b) } \\
\text { Mean (SD) }\end{array}$ \\
\hline OVERALL PERCEIVED RISK INDEX (Alpha=0.90) & $3.29(0.57)$ & $3.52(0.47)$ & $2.99(0.56) *$ \\
\hline $\begin{array}{l}\text { FINANCIAL RISKS ( Alpha= } \mathbf{0 . 5 0} \text { ) } \\
\text { I might spend more on my health because of my weight } \\
\text { I feel I am (will be) paid less because of my weight }\end{array}$ & $3.22(0.60)$ & $3.45(0.13)$ & $2.93(0.54)^{*}$ \\
\hline $\begin{array}{l}\text { PERFORMANCE//PHYSICAL RISKS (Alpha= 0.73) } \\
\text { I cannot do what I want because of my weight } \\
\text { My weight may cause many types of illness in future } \\
\text { My weight puts me in potential physical danger }\end{array}$ & $3.16(0.68)$ & $3.49(0.49)$ & $2.73(0.65)^{*}$ \\
\hline $\begin{array}{l}\text { PSYCHOLOGICAL RISKS (Alpha= 0.76) } \\
\text { I have a low self-esteem because of my weight } \\
\text { I feel discriminated because of my weight }\end{array}$ & $3.41(0.19)$ & $3.58(0.63)$ & $3.19(0.73)^{*}$ \\
\hline $\begin{array}{l}\text { SOCIAL RISKS (Alpha }=\mathbf{0 . 7 9 )} \\
\text { My friends and relatives will negatively judge me because of my weight } \\
\text { People usually consider me lazy because of my weight }\end{array}$ & $3.40(0.66)$ & $3.59(0.53)$ & $3.22(0.76)^{*}$ \\
\hline
\end{tabular}

(a) 1=Strongly agree; $4=$ =Strongly disagree, with 1 representing the highest perceived risk and 4 indicating the lowest perceived risk for each item.

(b) This classification is based on self-perception of weight.

$* \mathrm{p} \leq 0.01$

Table 4: Association between perceived weight risk and behaviors

\begin{tabular}{|c|c|c|c|c|}
\hline \multirow{2}{*}{ Behavior } & \multicolumn{2}{|c|}{ Perceived Weight Risk (a) } & \multirow{2}{*}{ Chi Square } & \multirow[b]{2}{*}{$\mathrm{p}$} \\
\hline & $\begin{array}{c}\text { High } \\
\mathrm{n}(\%)\end{array}$ & $\begin{array}{c}\text { Low } \\
\mathrm{n}(\%)\end{array}$ & & \\
\hline $\begin{array}{l}\text { Fat intake (b) } \\
\text { High } \\
\text { Low }\end{array}$ & $\begin{array}{c}26(74.3) \\
9(25.7)\end{array}$ & $\begin{array}{ll}39 & (76.5) \\
12 & (23.5)\end{array}$ & 0.54 & NS \\
\hline $\begin{array}{l}\text { Physical activity (c) } \\
\text { High } \\
\text { Low }\end{array}$ & $\begin{array}{c}30(85.7) \\
5(14.3)\end{array}$ & $\begin{array}{l}39(76.5) \\
12(23.5)\end{array}$ & 1.11 & NS \\
\hline
\end{tabular}

(a) Perceived weight risk categories were created by taking all 9 statements into consideration (Ranges of scores between 9 and 36). The cutoff point was 27 . The scores between 9 and 27 were considered high perceived risk and the scores above 27 up to 36 were considered low perceived risk.

(b) Fat intake behavior was measured with 6 questions (Yes or No answers), The scale was created within the 6 through 12 ranges. Those who scored between 9-12 was considered high fat intake group; while those scored between 6 through 8 was considered low fat intake group.

(c) Self-reported physical activity levels were determined by the responses to the question: "Which of the following best describes your current level of physical activity? Response categories were: I am not physically active at all and I engage in light activities, (these two responses were collapsed into "low" activity; I am moderately active and I am vigorously active (collapsed into "high" activity) 
As can be seen in Table 4, Chi square analysis showed that perceived weight risk, and fat intake and physical activity were independent. There was no significant difference between participants who perceive a high weight risk and those who perceive a low weight risk in terms of their fat intake behaviors. In other words, $74.3 \%$ of participants who perceived a high weight risk and $76.5 \%$ of participants who perceived a low weight risk reported consuming high fat foods, which is an indication of high calorie intake that may lead to weight gain. This finding may imply that overweight students in this study did not engage in healthy behaviors such as low fat intake in an effort to manage their weight risks. Similar to fat intake behavior, there was no statistically significant difference in physical activity levels between high risk perception and low risk perception groups (Table 4). This finding is in contrast to the results of Haase, et al.'s study (2004) which showed in university students from 23 countries that the leisure-time physical activity was higher in those students with stronger health-benefit beliefs. Although we did not determine health-benefit beliefs related to physical activity, we expected that participants who perceived a higher weight risk would engage in more physical activity. A Dutch study (Wammes et al. 2005) demonstrated that risk perceptions related to weight gain was the strongest predictor of intention to prevent weight gain. A significant effect of weight risk perception was also demonstrated for intention to eat healthy diets (Froush et al. 2005). In this study, we were not able to show the reflection of perceived weight risk on behaviors toward healthy eating or becoming more physically active.

\section{CONCLUSIONS AND IMPLICATIONS}

The adapted perceived risk model was tested in a small sample with reliable measures of the dimensions. The current research is pertinent from a theoretical perspective because it helps explain how normal and overweight consumers evaluate their perceived weight risks. Our findings also provide insights into behavioral outcomes. The findings, in general, indicated that participants who perceive themselves as overweight and normal differed in perception of their weight risks. Overweight consumers perceived a higher weight risk than their normal weight counterparts. However, this difference was not reflected in their fat intake behaviors and physical activity levels which are indications of weight management efforts.

Nonetheless, we acknowledge several limitations arising from the exploratory nature of the study. Since the sample size was small, more educated than general public, was from only one university and the survey did not adopt a random sampling method, the results from the multidimensional perceived weight risk should be interpreted with care. It is necessary to replicate the results in larger populations to enhance generalizability. In spite of its limitations, however, this study provides an attempt to examine the differences in perceived weight risks of two groups, namely those who perceive their weight "normal" and those who perceive themselves as "overweight", and their weight related behaviors. The study was cross-sectional in nature, and thus the causal link is difficult to verify between perceived risk and behavior. Researcher should conduct a longitudinal study to overcome this problem.

Understanding the perceived weight risks of populations under risk such as overweight or eating disorders might be useful in development of appropriate risk communication or health promotion strategies. Perceived weight risk awareness produces wariness or risk aversion that can lead to a variety of risk handling or reduction behaviors, including individual weight management strategies such as healthy eating and physical activity and more information seeking from trustworthy sources. By avoiding unhealthy behaviors (overeating, less physical activity etc), and by having reliable nutrition and health information, reduction of the unfavorable consequences in terms of physical, financial, social or psychological losses can be achieved. For example, high perceived weight risk groups can be used as a segment and risk perceptions may be a useful tool for designing intervention strategies to promote direct and personalized messages regarding healthy eating behavior and physical activity for a chosen segment. An improvement of the knowledge level on preventive tools is not a sufficient condition to improve individual risk management behavior. In spite of their knowledge of weight related risks, some individuals do not conform to the suggestions or recommendations and continue behaving in a way which exposes them to the risks. These groups need to understand the serious consequences of their weight and the impact of it on their lives, and then be ready for behavioral modification. For example, joining a weight management support group can be a way for positive reinforcement. 
There are several directions for future research. More research is needed to determine how perceived weight risk influences behavior in different ethnic and age groups, and different education levels for validating the model and its operational dimensions, and to determine how individuals can be motivated to engage in weight risk minimizing or eliminating strategies and activities.

\section{REFERENCES}

1. Anderson, P.M., K.F. Butcher and P.B. Levine (2003) Economic perspectives in childhood obesity. Economic Perspectives: Federal Reserve Bank of Chicago, 20-48

2. Bauer, R.A (1967) Consumer behavior as a risk taking, in D.F. Cox, ed., Risk Taking and Information Handling in Consumer Behavior. Boston: Harvard University Press

3. Brener, N.D., D.K. Eaton, R. Lowry, et al (2004) The association between weight perception and BMI among high school students. Obesity Research, 12(11): 1866-1874

4. Cawley, J. (2000) Body weight and women's labor market outcomes. National Bureau of Economic Research, Working Paper, No: 7841, August.

5. Cox, D.F (1967) Risk Taking and Information Handling in Consumer Behavior, Boston: Harvard University Press

6. Cunningham, S.M. (1967) The dimensions of perceived risk, in D.F. Cox, ed., Risk Taking and Information Handling in Consumer Behavior. Boston: Harvard University Press

7. Desmond, S.M., J.H. Price, N. Gray, et al. (1986) The etiology of adolescents' perceptions of their weight. Journal of Youth Adolescence, 461-474

8. Dowling, G.R. and R. Staelin (1994) A model of perceived risk and intended risk handling activity. Journal of Consumer Research, 21: 119-134

9. Festerand, T.A., D.R Synder and J.D.Tsalikis (1986) The influence of catalog versus store shopping and prior satisfaction on perceived risk. Journal of Academy of Marketing Sciences, 14(4): 28-36

10. Floyd, P.A., S.E. Mimms and C. Yelding (2008) Personal Health: Perspectives and Lifestyles. $4^{\text {th }}$ ed. Thomson/Wadsworth, Belmont, CA

11. Frewer, L., R. Shepherd and P. Sparks (1994) The relationship between perceived knowledge, control and risk associated with a range of food related hazards targeted at self, other people and society. Journal of Food Safety, 14: 19-40

12. Forsythe, S. and B. Shi (2003) Consumer patronage and risk perceptions in internet shopping. Journal of Business Research, 56: 867-875

13. Froush, D.L., P. Mellow and C. Lerman (2005) Behavioral consequences of testing for obesity risk. Cancer Epidemiology, Biomarkers and Prevention, 14(6): 1485-1489

14. Garner, S. (1986) Perceived risk and information sources in services purchasing. The Mid-Atlantic Journal of Business, 24(2): 49-58

15. Haase, A., A. Steptoe, J. Sallis, and J. Wardle (2004) Leisure-time physical activity in university students from 23 countries: Associations with health beliefs, risk awareness and national economic development. Preventive Medicine, 39(1): 182-190.

16. Ho, S.S. and V. Ng (1994) A study of consumers' perceived risk of electronic payment systems. International Journal of Bank Marketing, 12(4): 26-36

17. Jacoby, J. and L.B. Kaplan (1972) The components of perceived risk. Advances in Consumer Research, $1(1), 382-293$

18. Kaplan, L.B., G.J. Szybillo and J. Jacoby (1974) Components of perceived risk in product purchase: A cross validation. Journal of Applied Psychology, 59: 287-291

19. Ko, H., J. Jung, J. Kim and S. Shim (2004) Cross cultural differences in perceived risk of online shopping. Journal of Interactive Advertising, 2(4): 2-18

20. Kumanyika, S., J.F. Wilson and M. Guilford-Davenport (1993) Weight-related attitudes and behaviors of black women. Journal of American Dietetic Association, 35: 416-422

21. Nunnally, J. (1978) Psychometric Theory, $2^{\text {nd }}$ ed., McGraw-Hill, New York, NY

22. Peter, J.P and L.X. Tarpey (1975) A Comparative Analysis of three consumer decision strategies. Journal of Consumer Research , 2(June), 29-37 
23. Roux, L. and C. Donaldson (2004) Economics and Obesity: Costing the problem or evaluating solutions? Obesity Research, 12(2): 173-179

24. Schiffman, L.G., S. Schus and L. Winer (1976) Risk perception as a determinant of in-home consumption. Journal of Academy of Marketing Science, 4 (4):753-763

25. Schiffman, L. G. and L. Kanuk (2007) Consumer Behavior, $9^{\text {th }}$ ed., Pearson Education, Inc, Upper Saddle River: NJ

26. Slovic, P. (1992) Perception of risk: Reflections on the psychometric paradigm. In S. Krimskey and D. Golding, (eds.), Social Theories of Risk, Praeger: West Port

27. Stone, R. and K. Gronhaug (1993) Perceived risk: Further considerations for the marketing discipline. European Journal of Marketing, 27(3): 39-50

28. Strauss, R.S. (1999) Self-reported weight status and dieting in a cross-sectional sample of young adolescents: National Health and Nutrition Examination Survey III. Archives of Pediatric and Adolescence Medicine, 153: 741-747

29. The Behavior Consortium of the National Cancer Institute. Available at: http://www1.od.nih.gov/behaviorchange/measures/nutrition.htm.

30. The BRFSS (Behavioral Risk Factor Surveillance System) Available at: http://www.cdc.gov/bfrss.

31. Xie B, C. Ping Chou and D.S. Mertz, et al. (2006) Weight perception, academic performance and psychological factors in Chinese adolescents. American Journal of Health Behavior 30(2): 115-124.

32. Wammes, B., et al. (2005) Correlates of motivation to prevent weight gain: A cross sectional survey. International Journal of Behavioral Nutrition and Physical Activity, 2: 1-8

33. Zimmerman, G.L., C.G. Olsen and M.F. Bosworth (2000) A stages of change approach to helping patients change behavior. American Family Physician, March 1. 